\title{
Theoretical Assumptions for the Impact of Infrastructure Development on Economic Growth and Convergence
}

\author{
Alma Mačiulytė-Šniukienè \\ Vilnius Gediminas Technical University, Vilnius, Lithuania
}

\begin{abstract}
One of the areas in which all countries focus to achieve social and economic prosperity is infrastructure development. Moreover, the development of infrastructure is one of the European Union (EU) Cohesion Policy priorities. An increase in infrastructure development in less developed regions is expected to stimulate economic growth and reduce regional disparities. In EU Member States (MS), infrastructure is heavily funded. However, it remains unclear whether these investments have a positive impact on economic growth and convergence. This factor's effect is receiving increasing attention in scientific papers, but the approach to the impact of infrastructure investments on economic development is controversial. The results of empirical research on infrastructure development effects in previous studies also vary. Moreover, investigations usually involve assessing the impact of only one type of infrastructure development on the economic growth of one or a few countries, ignoring the implications for convergence, and do not consider the fact that the impact may occur after a certain period of time. Another limitation identified in some previous studies is that the impact of infrastructure development is assessed without considering other factors' impact. To evaluate the impact of infrastructure on economic growth and convergence in a comprehensive way and as accurately as possible, a theoretical model addressing the identified issues is needed. Considering this, we aim to provide theoretical assumptions and develop a model for the impact of infrastructure development on economic growth and convergence. To achieve this goal, the concept of infrastructure was disclosed, the main types of infrastructure were identified, analysis of previous studies was provided, and a theoretical model for assessment of infrastructure outcomes was formed.
\end{abstract}

Keywords: infrastructure; transport infrastructure; energy infrastructure; telecommunication infrastructure; economic growth; convergence.

Funding: This project has received funding from European Social Fund (project No 09.3.3LMT-K-712-19-0036) under grant agreement with the Research Council of Lithuania (LMTLT). 